\title{
К ВОПРОСУ ИЗОМЕРНОГО СОСТАВА ФЕНИЛАЛКАНОВ, ПОЛУЧАЮЩИХСЯ АЛКИЛИРОВАНИЕМ БЕНЗОЛА НОРМАЛЬНЫМИ АЛКЕНАМИ
}

\author{
(Представил О. Эйзен)
}

Из многочисленных исследований известно, что при алкилировании бензола олефинами получается равновесная смесь изомерных фенилалканов, которая не содержит лишь 1-фенилалкан.

Установлено, что от изомерного состава смеси фенилалканов, используемой для получения алкиларилсульфонатов, в значительной степени зависят поверхностно-активные и моющие свойства продукта, а также их биоразлагаемость.

Р. Д. Свишер ['] показал, что 2-фенилдодекан разлагается в речной воде примерно в 3 раза быстрее, чем 6-фенилдодекан. Им же установлено, что биодеградация растет с увеличением алкильной цепи.

Ф. В. Неволин, С. И. Файнгольд, Г. А. Краль-Осикина и Р. М. Томсон $\left[{ }^{2}\right]$ установили, что моющее действие 2- и 3-фенилдодекансульфона. тов одинаково и примерно в 2 раза выше, чем 4-, 5- и 6-фенилдодекансульфонатов. Таким образом, наиболее ценными с точки зрения охраны окружающей среды и потребителя, являются алкиларилсульфонаты с положением фенильной группы 2- и 3- относительно алкильной цепи.

Изучению изомерного состава и его зависимости от рода катализатора, температуры алкилирования и соотношения реагентов посвящено довольно много работ [9]. Данные об изомерном составе и условиях алкилирования приведены в табл. 1.

Целью настоящей работы являлось выявление факторов, приводящих к увеличению выхода 2-фенилалкана. Такими факторами могут быть катализатор, способ его получения, изменение температуры алкилирования.

Алкилирование бензола олефинами во всех случаях велось при следующих условиях:

Температура алкилирования $+10^{\circ} \mathrm{C}$, соотношение бензол : олефин в молях 8:1, общее время реакции 2 часа. Реакционная смесь после отделения катализатора дважды промывалась водой и после отгонки бензола анализировалась на хроматографе «Хром-42», снабженном интегратором IT-2 и печатающим устройством PT-1. Колонка 2,5 $\mathrm{M}$ $\varnothing 3$ мм, наполнитель 5\% XE-60 на хезасорбе AW-HMDC.

Расход водорода $30 \mathrm{~m} /$ мин, расход воздуха $0,3 \Omega / м u н$, газ-носитель азот, давление $0,9 \kappa P a$. Температура испарителя $270^{\circ}$, температура термостата ПИД $250^{\circ}$. Температура колонки для фенилгептанов $+120^{\circ}$, для фенилнонанов $+140^{\circ}$ для фенилундеканов $+160^{\circ}$ и для фенилтридеканов $+180^{\circ}$. 
i

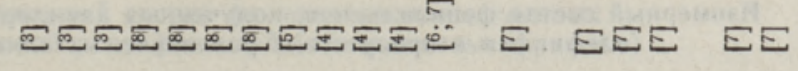

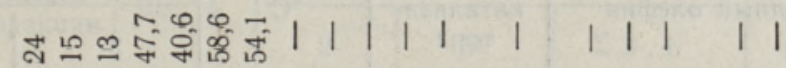

또으

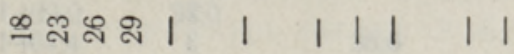

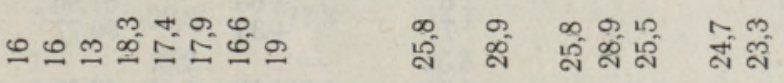

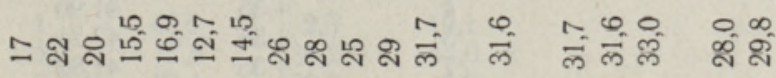

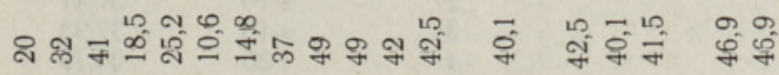

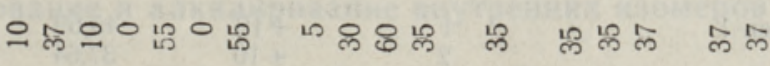

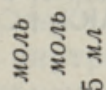

$8=0$

호은

$\ddot{1} \approx \frac{10}{0}$

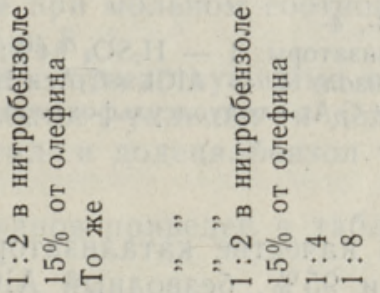

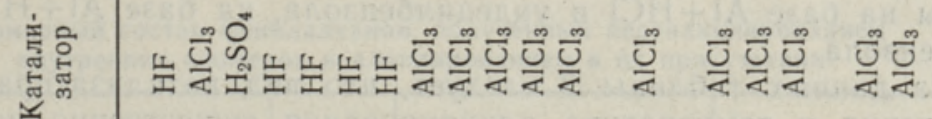

|

$\exists$

产

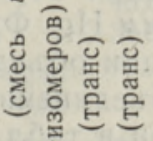

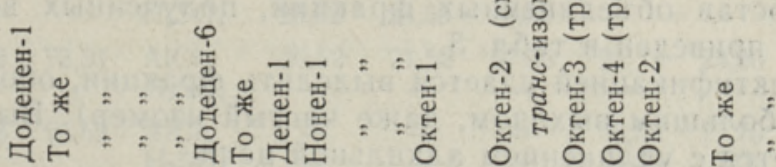


Изомерный состав фенилалканов, полученных алкилированием бензола олефинами в присутствии различных катализаторов

\begin{tabular}{|c|c|c|c|c|c|}
\hline \multirow{2}{*}{ Исходный олефин } & \multirow{2}{*}{$\begin{array}{l}\text { Номер } \\
\text { катализа- } \\
\text { тора }\end{array}$} & \multirow{2}{*}{${ }^{\circ} \mathrm{C}$} & \multicolumn{3}{|c|}{ Изомеры, \% } \\
\hline & & & $2-$ & 3. & $4-, 5-, 6-, 7-$ \\
\hline Гептен-1 & $\begin{array}{l}1 \\
2 \\
3 \\
4 \\
5 \\
6 \\
7\end{array}$ & $\begin{array}{l}+10 \\
+10 \\
+10 \\
+35 \\
+35 \\
+60 \\
+35\end{array}$ & $\begin{array}{l}44,11 \\
54,59 \\
51,05 \\
52,93 \\
49,85 \\
51,96 \\
50,77\end{array}$ & $\begin{array}{l}55,35 \\
45,41 \\
48,95 \\
47,07 \\
50,15 \\
48,04 \\
49,23\end{array}$ & \\
\hline & $\begin{array}{l}2 \\
3 \\
4 \\
5 \\
7\end{array}$ & $\begin{array}{l}+10 \\
+10 \\
+35 \\
+35 \\
+35\end{array}$ & $\begin{array}{l}42,36 \\
42,36 \\
41,96 \\
42,21 \\
41,82\end{array}$ & $\begin{array}{l}27,22 \\
27,56 \\
27,70 \\
27,48 \\
27,69\end{array}$ & $\begin{array}{l}30,41 \\
30,07 \\
30,44 \\
30,31 \\
30,59\end{array}$ \\
\hline Ундецен-1 & $\begin{array}{l}1 \\
2 \\
3 \\
4 \\
5 \\
7\end{array}$ & $\begin{array}{l}+10 \\
+10 \\
+10 \\
+35 \\
+35 \\
+35\end{array}$ & $\begin{array}{l}37,1 \\
37,41 \\
37,93 \\
35,79 \\
36,04 \\
35,32\end{array}$ & $\begin{array}{l}26,35 \\
24,72 \\
23,33 \\
22,80 \\
23,31 \\
24,00\end{array}$ & $\begin{array}{c}36,55 \\
37,87 \\
38,74 \\
41,41 \\
40,64 \\
40,68\end{array}$ \\
\hline Тридецен-1 & $\begin{array}{l}1 \\
2 \\
3 \\
4 \\
5 \\
7\end{array}$ & $\begin{array}{l}+10 \\
+10 \\
+10 \\
+35 \\
+35 \\
+35\end{array}$ & $\begin{array}{l}45,69 \\
37,64 \\
37,23 \\
35,76 \\
36,22 \\
36,34\end{array}$ & $\begin{array}{l}23,12 \\
21,28 \\
22,86 \\
22,08 \\
22,21 \\
22,16\end{array}$ & $\begin{array}{l}31,19 \\
41,418 \\
39,91 \\
42,16 \\
41,57 \\
41,50\end{array}$ \\
\hline
\end{tabular}

* $\Sigma$ 3-, 4-

Катализаторы: $1-\mathrm{H}_{2} \mathrm{SO}_{4} 94 \% ; 2-\mathrm{Al}+\mathrm{HCl}(\Gamma)+\mathrm{C}_{11} \mathrm{Ar} ; 3-\mathrm{Al}+\mathrm{HBr}$ (Г) + нзопропилбензол; $4-\mathrm{AlCl}_{3}+\mathrm{C}_{7} \mathrm{Ar}+\mathrm{H}_{2} \mathrm{O}$ (следы); $5-\mathrm{AlCl}_{3}+\mathrm{C}_{11} \mathrm{Ar}+\mathrm{H}_{2} \mathrm{O}$ (следы); 6 $\mathrm{AlCl}_{3}+\mathrm{C}_{7} \mathrm{Ar}+$ толуолсульфохлорид; $7-\mathrm{AlCl}_{3}$.

В качестве катализаторов использовались серная кислота концентрации $95 \%$, безводный $\mathrm{AlCl}_{3}$, каталитические комплексы на базе безводного $\mathrm{AlCl}_{3}$ фенилгептана и фенилундекана, каталитические комплексы на базе $\mathrm{Al}+\mathrm{HCl}$ и ундецилбензола, на базе $\mathrm{Al}+\mathrm{HBr}$ и изопропилбензола.

Из данных таблицы 2 следует, что вид катализатора, способ его получения и температура алкилирования существенно не влияют на изомерный состав выходящих фенилалканов.

Далее была выяснена возможность выделения индивидуальных фенилалканов с помощью ректификации. Для этого были синтезированы октилбензол, децилбензол, ундецилбензол и додецилбензол.

Ректификация осуществлялась на колонке эффективностью 12 ТT, вакуум 5-6 мм Нg. Фракции анализировались на хроматографе, и идентичные фракции объединялись.

Состав объединенных фракций, полученных вакуумной ректификацией, приведен в табл. 3.

Ректификацией удается выделить фракции, обогащенные 2-изомером (с небольшим выходом, даже чистый изомер). Выход 2-изомера увеличивается с удлинением алкильной цепи. 
Изомерный состав фенилалканов, выделенных вакуумной ректификацией (объединенные фракции)

\begin{tabular}{|c|c|c|c|c|c|c|}
\hline \multirow{2}{*}{$\begin{array}{c}\text { Исходный } \\
\text { олефин }\end{array}$} & \multirow{2}{*}{$\begin{array}{l}\text { Номер } \\
\text { фракции }\end{array}$} & \multirow{2}{*}{ Bec. $\%$} & \multicolumn{4}{|c|}{ Изомерный состав, \% } \\
\hline & & & 2 - & 3- & $\Sigma 3-, 4-$ & $4-, 5-, 6-$ \\
\hline Октен-1 & $\begin{array}{l}1 \\
2 \\
3\end{array}$ & $\begin{array}{l}12,3 \\
59,9 \\
27,8\end{array}$ & $\begin{array}{l}27,6 \\
39,0 \\
64,4\end{array}$ & $\begin{array}{l}35,0 \\
34,0\end{array}$ & 35,6 & $\begin{array}{l}37,4 \\
27,0\end{array}$ \\
\hline Децен-1 & $\begin{array}{l}1 \\
2 \\
3\end{array}$ & $\begin{array}{l}27,3 \\
51,9 \\
20,8\end{array}$ & $\begin{array}{l}21,2 \\
44,9 \\
77,3\end{array}$ & $\begin{array}{l}27,1 \\
25,3 \\
14,7\end{array}$ & & $\begin{array}{r}51,7 \\
28,8 \\
8,0\end{array}$ \\
\hline Ундецен-1 & $\begin{array}{l}1 \\
2 \\
3\end{array}$ & $\begin{array}{l}48,2 \\
23,3 \\
28,4\end{array}$ & $\begin{array}{l}\overline{42,0} \\
95,6\end{array}$ & $\begin{array}{l}26,5 \\
38,2\end{array}$ & 4,4 & $\begin{array}{l}73,5 \\
19,8\end{array}$ \\
\hline Додецен-1 & $\begin{array}{l}1 \\
2 \\
3 \\
4\end{array}$ & $\begin{array}{l}43,9 \\
17,8 \\
18,4 \\
19,9\end{array}$ & $\begin{array}{r}2,5 \\
39,2 \\
79,3 \\
100\end{array}$ & $\begin{array}{r}19,1 \\
44,0 \\
8,9 \\
-\end{array}$ & 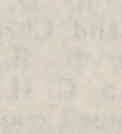 & $\begin{array}{c}78,5 \\
16,8 \\
1,8 \\
-\end{array}$ \\
\hline
\end{tabular}

\section{Переалкилирование и алкилирование внутренних изомеров}

Возможность выделения ректификацией чистых 2-изомеров позволяет увеличить выход этих изомеров путем переалкилирования внутренних изомеров.

Смесь внутренних изомеров децилбензола и ундецилбензола подвергалась обработке $\mathrm{AlCl}_{3}$ при $35^{\circ}$ в бензоле при мольном соотношении бензола к алкилбензолу в пересчете на олефин $8: 1$.

Изучалось также алкилирование бензола соответствующими олефинами в присутствии внутренних изомеров: октил-, ундецил- и додецилбензол получали в присутствии $\mathrm{AlCl}_{3}$, а октил- и додецилбензол также в присутствии $\mathrm{H}_{2} \mathrm{SO}_{4}$.

Изомерный состав полученных фенилалканов приведен в табл. 4.

Таблица 4

Изомерный состав фенилалканов, полученных переалкилированием внутренних изомеров и алкилированием в их присутствии

\begin{tabular}{|c|c|c|c|c|c|c|c|c|c|c|}
\hline \multirow{2}{*}{$\begin{array}{c}\text { Исходный } \\
\text { олефин }\end{array}$} & \multicolumn{3}{|c|}{$\begin{array}{c}\text { Исходная смесь } \\
\text { внутренних изомеров }\end{array}$} & \multirow{2}{*}{$\begin{array}{c}\text { Ката- } \\
\text { лизатор }\end{array}$} & \multicolumn{3}{|c|}{ Переалкилирование } & \multicolumn{3}{|c|}{ Алкилирование } \\
\hline & $2-$ & $3-$ & $\begin{array}{c}4-, 5- \\
6-\end{array}$ & & 2 - & 3- & $\begin{array}{c}4-, 5- \\
6-\end{array}$ & 2 - & $3-$ & 4-, 5- \\
\hline Окт & 40,47 & 30,90 & 28,84 & $\begin{array}{l}\mathrm{AlCl}_{3} \\
\mathrm{H}_{2} \mathrm{SO}_{4}\end{array}$ & & & & $\begin{array}{l}45,62 \\
39,97\end{array}$ & $\begin{array}{l}27,69 \\
29,92\end{array}$ & $\begin{array}{l}26,68 \\
30,11\end{array}$ \\
\hline Дец & 25,71 & 25,98 & 49,01 & $\begin{array}{l}\mathrm{AlCl}_{3} \\
\mathrm{H}_{2} \mathrm{SO}_{4}\end{array}$ & $\begin{array}{l}34,17 \\
25,52\end{array}$ & $\begin{array}{l}23,47 \\
25,59\end{array}$ & $\begin{array}{l}42,40 \\
48,88\end{array}$ & & & \\
\hline $\mathrm{y}_{\text {нде }}$ & $\overline{-}$ & 26,49 & 73,51 & $\begin{array}{l}\mathrm{AlCl}_{3} \\
\mathrm{H}_{2} \mathrm{SO}_{4}\end{array}$ & $\frac{20,52}{-}$ & $\stackrel{21,52}{-}$ & $\stackrel{57,96}{-}$ & 21,73 & 23,20 & $\stackrel{55,07}{-}$ \\
\hline Додецен-1 & $\overline{-}$ & 6,48 & 93,52 & $\begin{array}{l}\mathrm{AlCl}_{3} \\
\mathrm{H}_{2} \mathrm{SO}_{4}\end{array}$ & $\overline{-}$ & $\overline{-}$ & $\frac{-}{-}$ & $\begin{array}{r}26,09 \\
4,36\end{array}$ & $\begin{array}{r}17,70 \\
7,07\end{array}$ & $\begin{array}{l}56,21 \\
88,57\end{array}$ \\
\hline
\end{tabular}




\title{
Выводы
}

1. При алкилировании в присутствии галоидов алюминия изомерный состав фенилалканов не зависит от способа получения катализаторного комплекса, от температуры алкилирования, от галоида, входящего в состав галоида алюминия. Содержание 2-фенилалканов с увеличением длины алкильной цепи уменьшается. 2. Практически возможно выделение чистых 2-фенилалканов с длиной цепи более 10 атомов углерода вакуумной ректификацией на колонке эффективностью 12 ТТ. 3. С целью увеличения выхода 2-изомера возможно переалкилирование внутренних изомеров в присутствии $\mathrm{AlCl}_{3}$. При переалкилировании относительное содержание 2-изомера значительно ниже, чем при прямом алкилировании бензола $\alpha$-олефинами.

\section{Л И Т Е Р А Т У Р А}

1. Swisher, R. D. Intermediates in ABS (alkylbenzenesulfonates) degradation. Soap and Chem. Specialities, 1963, v. 39, N 7, p. 47-50, 95.

2. Неволин Ф. В., Краль-Осикина Г. А., Бушуева Е. И., Файн гольд С. И., Т ом сон Р. М. Исследование поверхностно-активных свойств и моющей способности растворов индивидуальных 1-, 2-, 3-, 4-, 5-, 6-фенилдодекан-сульфонатов. - Тр. ВНИИЖ, 1967, вып. XXVI, с. $356-368$.

3. O1s o n, A. C. Alkylation of aromatic with 1-alkenes. - Ind. Eng. Chem., 1960, v. $52, \mathrm{~N} 10$, p. $833-836$.

4. Файнггльд С. И., К ор в М. И., Т ээдум яэ В. К. О некоторых закономерностях алкилирования бензола 1-ноненом. - Изв. АН ЭССР, Хим., Геол., 1967, т. $16 / 3$, с. $217-222$.

5. Skrzypek, I., Gasztych, D. Alkilowanie benzenu $\alpha$-olefinami $\mathrm{C}_{10}$ i $_{12}$. Przemysl chemiczny, 1972 , v. 51 , N 6, p. $359-362$.

6. В ооре Х. Ю. Алкилирование ароматических углеводородов моноолефинами С-5, С-12. - Автореф. дис. Таллин, 1964.

7. Ф а йнгольд С. И., Л е смент Т. Н., С теп анов а Г. Г. Алкилирование бензола октенами. - В сб.: Синтез и применение новых поверхностно-активных веществ. Таллин, 1973 , с. $15-22$.

8. Alul, H. R., McEwa n, G. I. Solvent effects in the alkylation of benzene with 1-dodecene and trans-6-dodecene in the presence of hydrogen fluoride. J. Org. Chem., 1967, N 32, p. 3365-3369.

9. Файнгольд С. И., Л есмен т Т. Н. Механизм миграции двойной связи в алкенах под действием кислотных катализаторов. - В сб.: Синтез и применение новых поверхностно-активных веществ. Таллин, 1973, с. 8-14.

\author{
Ннститут химии \\ Академии наук Эстонской ССР
}

Поступила в редакцию 24/IV 1980

\section{A. RESETILOV, Tatjana LESMENT, S. FAINGOLD}

\section{BENSEENI ALKUOLIMISEL $\alpha$-OLEFIINIDEGA SAADUD FENOOLALKAANIDE ISOMEERNE KOOSTIS}

Artiklis on esitatud järeldus, et erinevates tingimustes sünteesitud fenüülalkaanide isomeerne koostis ei sōltu oluliselt katalüsaatori liigist ega temperatuurist. Vaakuumrektifikatsioon vōimaldab såda 2- ja 3-fenüülalkaanidega rikastatud segu ning puhta 2 -fenüülalkaani. Siseisomeeride ümberalküülimisel sünteesi tingimustes tekkiv isomeeride segu sisaldab vähem 2 -isomeeri kui otsesünteesiga saadud produkt.

\section{A. RESHETILOV, Tatyana LESMENT, S. FAINGOLD}

\section{BENZENE ALKYLATION WITH $\alpha$-OLEFINES}

The paper deals with research into the alkylation of benzene with $\alpha$-olefines under various conditions. The isomerization of phenylalkanes was studied. Pure 2-phenylalkanes and mixtures of 2- and 3-phenylalkanes were prepared by vacuum rectification. 